\title{
Evaluation of Paraclinical Methods in diagnosis of Foreign Body and its complications compared to operating room findings in patients with oral, pharyngeal and esophageal symptoms in Amir A'lam Hospital
}

\author{
Reza Erfanian, Ardavan Tajadini, Saeed Sohrabpour, Keyvan Aghazadeh, \\ Abdolhossein Mehdinezhad, Ebrahim Karimi \\ Otorhinolaryngology Research Center, Tehran University of Medical Sciences, Tehran, Iran
}

\begin{abstract}
Foreign Body (FB) swallowing is one of the most common medical emergencies in the world. This injury can cause mortality and morbidity in all age groups. This study aimed to evaluate the paraclinical methods in diagnosis of foreign body and its complications compared to operating room findings in patients with oral, pharyngeal and esophageal symptoms. This was a retrospective study. All patients referred to the ENT (Ear, Nose, Throat) department of Amir A'lam hospital with complaints of foreign body swallowing admitted in the operating room were studied. The patients' information including demographic information, type of swallowed body, paraclinical information and operating room findings were extracted from the patients' records. This study was performed on 219 patients admitted to ENT clinic. The mean age of the patients was $45.10 \pm 20.61$ years. The highest and the lowest frequencies for foreign body type were chicken bone in 61 cases $(28.31 \%)$ and disk battery in 1 case $(0.5 \%)$. The most and the least frequency of complaints after foreign body type were dysphagia in 129 cases $(58.9 \%)$ and neck tenderness in 7 cases $(3.19 \%)$. Computerized Tomography (CT) scan findings and operative findings were almost same except in two cases. Kappa agreement for lateral neck and observation in the operating room was $50.5 \%$ (P $<0.001$ ) and WBC count was significantly higher in patients with complications $(\mathrm{P}=0.010)$.
\end{abstract}

\footnotetext{
Correspondece: Ebrahim Karimi, Otolaryngology Research Center, Tehran University of Medical Sciences, Tehran, Iran.

E-mail: karimiebrahim2019@gmail.com

Key words: Foreign body; operating room; CT scan.

Conflict of interest: No one. This work was not supported by any grant.

Ethics approval and consent to participate: The manuscript does not contain any individual person's data in any form.

Received for publication: 12 February 2020.

Accepted for publication: 28 February 2020.

This work is licensed under a Creative Commons Attribution 4.0 License (by-nc 4.0).

C Copyright: the Author(s), 2020

Licensee PAGEPress, Italy

Emergency Care Journal 2020; 16:8726

doi:10.4081/ecj.2020.8726
}

According to the results, foreign bodies diagnosed with lateral neck can be reliable to make a decision based on it in patients with foreign bodies. High WBC count implicated in complicated foreign body cases.

\section{Introduction}

Foreign body swallowing is one of the most common medical emergencies in the world that can occur intentionally or accidentally. ${ }^{1}$ Foreign body swallowing can affect all ages, but it is more common in children under the age of 5 years and in toothless people. ${ }^{2.3}$ This injury can cause mortality and morbidity in all age groups, of which the most frequent victims are children aged 1 to 3 years old. ${ }^{4,5}$ Some diseases such as esophageal stenosis and neuromuscular and mechanical problems have been implicated as predisposing factors for foreign body in adults. ${ }^{6}$ The type of swallowed foreign body has a wide range including metallic and nonmetallic objects, sharp objects such as glass and locks pins, fish bone, as well as circle objects such as coins and toys in infants. ${ }^{7,8}$ The most common locations for foreign bodies are age-varying, and overall, the highest manifestation of 5-year-olds is similar to that of adults. ${ }^{9}$ Vomiting, odynophagia, dysphagia, and drooling are common symptoms of foreign body ingestion, and if the foreign body is large, may cause airway obstruction. Delay in diagnosis and removal may cause obstruction, deep neck abscesses, esophageal perforation and mediastinitis. ${ }^{10,11}$ Rapid removal of the foreign body reduces the risk of perforation. Therefore, the foreign body should be removed as soon as possible by the most common method of removal of the foreign body through esophagoscopy. ${ }^{12-14}$

One of the important diagnostic methods for the foreign body is to perform radiological imaging and these methods can be used in cases where the foreign body is absent from taking patients to the operating room and potentially performing rigid esophagoscopy. ${ }^{15}$ In this study, record of patients with suspected foreign body that had been gone the operating room of Amir A'lam analyzed and all of the relevant imaging including simple X-rays and Computerized Tomography (CT) scans were reviewed. We were also considering potential and fatal complications of foreign bodies to test the ability of pre-clinical studies to detect these complications in accordance with the findings of the operating room.

\section{Materials and Methods}

\section{Study design and setting}

This was a retrospective study. All patients admitted to the Ear, Nose, Throat (ENT) department of Amir A'lam hospital with complaints of swallowed foreign body how had been gone operating 
room were selected in 2018. The patients' information including demographic characteristics, type of swallowed object, presentation time after swallowing foreign body, symptoms, visibility of foreign body by esophagoscopy, laceration, perforation, abscess and external approach, radiologic findings lateral graph and computed tomography reports, leukocytosis and length of hospitalization were extracted from the records of hospitalized patients. Inclusion criteria were all patients admitted with foreign body swallowing and exclusion criteria were lack of hospitalization, incomplete records and patient dissatisfaction.

\section{Statistical analysis}

Qualitative data were reported as percentage and frequency. Quantitative data were reported as mean $\pm \mathrm{SD}$. Chi-square test was used to investigate the relationship between the qualitative variables. Kappa statistic was used to assess the degree of agreement between different diagnostic methods. $\mathrm{P}$ value $<0.05$ was considered significant. The data were analyzed using SPSS version 21 software.

\section{Results}

This study was carried out on 219 patients admitted to the ENT department of Amir A'lam hospital. The mean age of the patients was $45.10 \pm 20.61$ years (ranging from 1.5 years with swallowed coin to 84 years with swallowed fish bone). There were 114 males $(52.1 \%)$ and 105 females (47.9\%). The mean number of days past foreign body ingestion at the time of hospital admission was $1.62 \pm 1.30$ days (ranging from 1 to 7 days). The most common cause of foreign body was chicken bone $(28.31 \%)$ and the least common cause was disk battery $(0.5 \%)$. The distribution of foreign body frequency by type is shown in Table 1. The highest frequency of foreign body complaints was related to dysphagia in 129 patents $(58.9 \%)$ and the lowest was tenderness of the neck in 7 patents (3.19\%) (Table 2). Of the 198 cases performed using lateral neck, 185 cases were observed in the operating room and 13 cases were not observed (Table 3). Kappa agreement for lateral neck and observation in operating room was $50.5 \%(\mathrm{P}<0.001)$.

Correlation of foreign body observation in CT scan with operating room findings was investigated. In 50 cases $\mathrm{CT}$ scan was performed, foreign body was observed but in the two cases it was not observed in the operating room. One of them has had garlic and the other fish bone beneath the mucosa (Figure 1).

Complications of the operating room were evaluated and observed for 16 patients $(7.3 \%)$ including two perforations and 14 abscesses. The mean heart rate, body temperature, length of hospitalization, drooling and WBC were evaluated in the two groups with/without complications. The results showed that white blood cell count was significantly higher in patients with complications $(\mathrm{P}=0.010)$. Table 4 shows that the other variables were not significantly different. The results also showed that there was a significant relationship between leukocytosis and drooling $(\mathrm{P}<0.05)$.

The study showed that CT scans were consistent with intraoperative findings in the diagnosis of foreign body complications $(\mathrm{P}<0.001)$. Table 5 shows the number of matching CT scans with intraoperative findings in the diagnosis of foreign body complications. The relationship between foreign body and morbidity was investigated. The results showed that the most common type of foreign body that caused abscess was fish bone but was not statistically significant $(\mathrm{P}>0.05)$. In addition, there was no statistically significant relationship between the ingested body and the observed complications $(\mathrm{P}>0.05)$ (Table 6).
Table 1. The distribution of foreign body frequency by type.

\begin{tabular}{|ccc|}
\hline Type & Frequency & Percent \\
\hline Battery & 1 & 0.5 \\
Metal object & 7 & 3.19 \\
\hline Denture & 9 & 4.1 \\
Coin & 15 & 6.8 \\
\hline Unknown object & 31 & 14.15 \\
\hline Fish bone & 46 & 21 \\
\hline Meat bone & 49 & 22.83 \\
\hline Chicken bone & 61 & 28.31 \\
\hline Total & 219 & 100 \\
\hline
\end{tabular}

Table 2. The distribution of foreign body complaints.

\begin{tabular}{|ccc|}
\hline Type & Frequency & Percent \\
\hline Dysphagia & 129 & 58.9 \\
\hline Odynophagia & 121 & 55.2 \\
\hline Throat foreign body feeling & 81 & 36.9 \\
\hline Vomiting & 57 & 26 \\
\hline Respiratory distress & 23 & 10.5 \\
\hline Retrosternal chest pain & 22 & 10.4 \\
\hline Drooling & 12 & 5.4 \\
\hline Tenderness at the touch of the neck & 7 & 3.19 \\
\hline
\end{tabular}

Table 3. Distribution of cases using lateral neck and observation in operating room.

\begin{tabular}{lccc} 
Lateral FB & \multicolumn{2}{c}{ Operation room FB observation } & Total \\
& No & Yes & \\
Yes & 1 & 197 & 198 \\
No & 8 & 13 & 21 \\
\hline Total & 9 & 210 & 219 \\
\hline
\end{tabular}

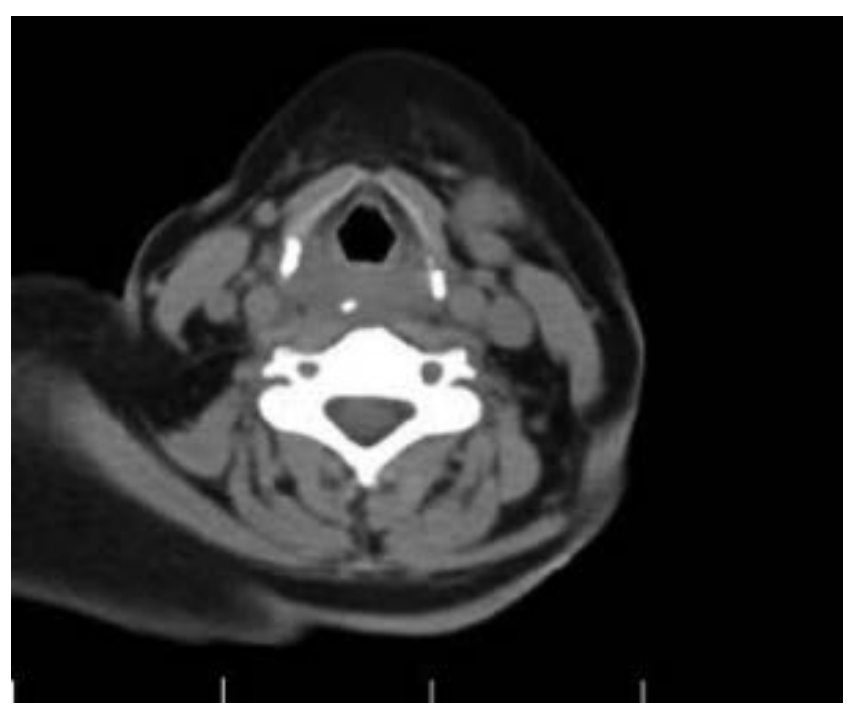

Figure 1. Axial CT scan image of patient with submucosal bone foreign body in retropharyngeal space: During rigid endoscopic evaluation in operation room we did not find foreign body probably due to deep submucusal location. 


\section{Discussion}

In the present study, the paraclinical methods in diagnosis of foreign body and its complications compared to operating room findings in patients with oral, pharyngeal and esophageal symptoms were evaluated. Swallowed disk battery was the least common cause of foreign body. Regarding symptoms, the highest frequency of foreign body complaints was dysphagia in about $60 \%$ of the patients and the lowest was tenderness of the neck in $3 \%$ of the patients. Approximately $93 \%$ of diagnosed cases with lateral neck was observed in the operating room with 50.5 kappa agreement. Regarding complications, there were two perforations and 14 abscesses, and high white blood cell count and drooling were significantly higher in patients with complications.

In a study by Sharafi et al., the most common complaint of foreign body ingestion was dysphagia and the most common cause of

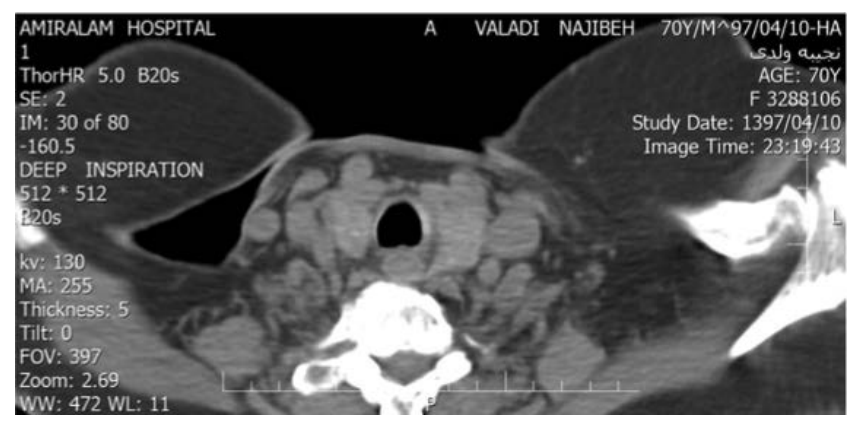

Figure 2. Axial CT scan image of patient with severe odynophagia which occurrd after garlic ingestion: During rigid endoscopic evaluation we did not find foreign body probably due to movement of object toward stomach because of decreasing upper esophageal sphincter tone by anesthetic paralyzing agent.

Table 4. The mean heart rate, body temperature, length of hospitalization, drooling and WBC in the two groups of patients with/without complications.

\begin{tabular}{|c|c|c|c|c|c|c|}
\hline \multicolumn{2}{|l|}{ Complication } & $\mathbf{N}$ & Mean & SD & $\mathrm{t}$ & P value \\
\hline Temperature & $\begin{array}{l}\text { No } \\
\text { Yes }\end{array}$ & $\begin{array}{c}203 \\
16\end{array}$ & $\begin{array}{l}36.97 \\
37.26\end{array}$ & $\begin{array}{l}0.324 \\
0.713\end{array}$ & -1.656 & 0.118 \\
\hline Heart Rate & $\begin{array}{l}\text { No } \\
\text { Yes }\end{array}$ & $\begin{array}{c}203 \\
16\end{array}$ & $\begin{array}{l}86.42 \\
87.38\end{array}$ & $\begin{array}{l}3.95 \\
2.91\end{array}$ & -0.947 & 0.345 \\
\hline Blood Pressure & $\begin{array}{l}\text { No } \\
\text { Yes }\end{array}$ & $\begin{array}{c}203 \\
16\end{array}$ & $\begin{array}{l}1.01 \\
1.00\end{array}$ & $\begin{array}{l}0.09 \\
0.00\end{array}$ & 0.397 & 0.692 \\
\hline Time of Hospitalization & $\begin{array}{l}\text { No } \\
\text { Yes }\end{array}$ & $\begin{array}{c}203 \\
16\end{array}$ & $\begin{array}{l}1.87 \\
2.00\end{array}$ & $\begin{array}{l}0.70 \\
0.73\end{array}$ & -0.721 & 0.471 \\
\hline White blood cell & $\begin{array}{l}\text { No } \\
\text { Yes }\end{array}$ & $\begin{array}{c}203 \\
16\end{array}$ & $\begin{array}{l}6204.93 \\
9556.25\end{array}$ & $\begin{array}{l}1772.47 \\
4558.79\end{array}$ & -2.923 & 0.010 \\
\hline Drooling & $\begin{array}{l}\text { No } \\
\text { Yes }\end{array}$ & $\begin{array}{c}203 \\
16\end{array}$ & $\begin{array}{l}1.08 \\
1.25\end{array}$ & $\begin{array}{l}0.27 \\
0.44\end{array}$ & -1.465 & 0.162 \\
\hline
\end{tabular}

Table 5. Compatibility of CT scans with intraoperative findings in the diagnosis of foreign body complications.

\begin{tabular}{|c|c|c|c|c|c|c|}
\hline \multirow{2}{*}{\multicolumn{2}{|c|}{ Variable }} & \multicolumn{3}{|c|}{ Operation room complication } & \multirow{2}{*}{\multicolumn{2}{|c|}{$\mathrm{P} \quad$ value }} \\
\hline & & Perforation & Abscess & No & & \\
\hline CT & No & 0 & 0 & 39 & $<0.001$ & \\
\hline Complication & Perforation & 2 & 0 & 0 & & \\
\hline & Cervical abscess & 0 & 9 & 0 & & \\
\hline & & 2 & 9 & 39 & & \\
\hline
\end{tabular}

Table 6. Type of foreign body by operating room complication.

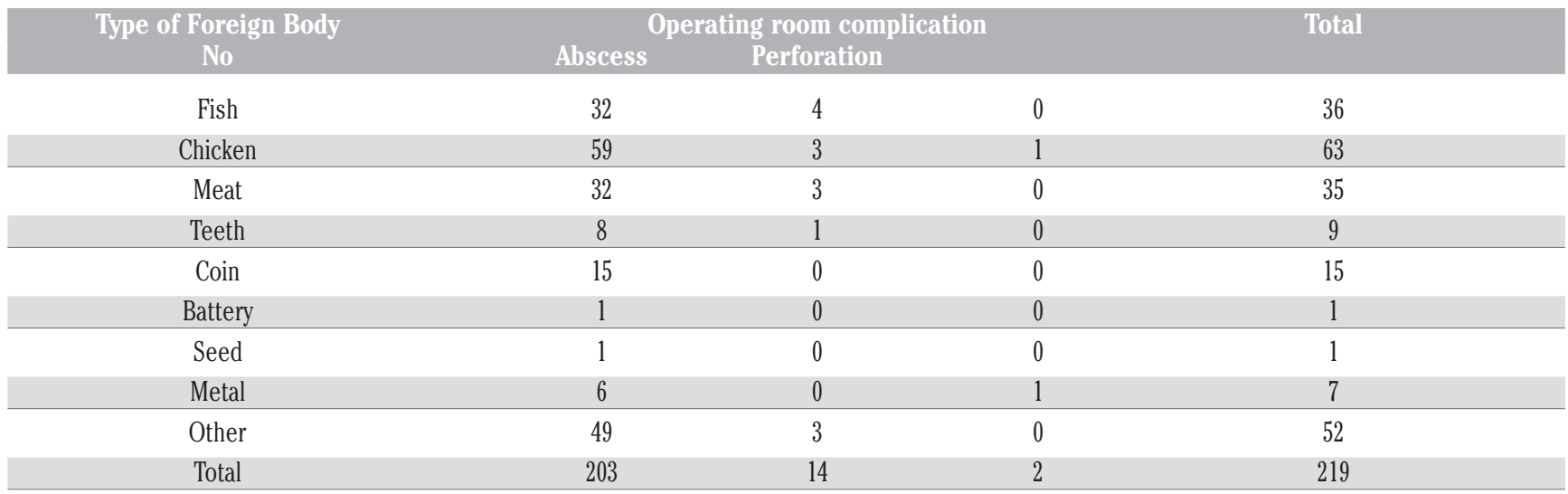


foreign body was chicken bone. In the under 15 years age group, the most common foreign body was coin as in our study. Also, the complications of foreign body swallowing were erosion, ulcer, mucosal rupture, re-admission, esophageal rupture and abscess, respectively. ${ }^{16}$ According to the endoscopic results, the most common location of the foreign body was found in the upper third of the esophagus. The results of this study were in consistent with our study and study of Karimaneh and Najafi, that is, the most common cause of foreign body was chicken bone. Like our study, coin was responsible to the most common cause of foreign body in children. ${ }^{17}$ In a study by Pirzadeh et al., the most common and the least common cause of foreign body was chicken bone and coin, respectively, in such a way that was consistent with our results. ${ }^{18}$ Regarding the diagnostic method, $41.4 \%$ were diagnosed with simple radiography and the rest were diagnosed with endoscopy and only one case of swallow wing was diagnostic with barium. ${ }^{16}$ It should be noted that a higher diagnosis with lateral X-ray may be due to the use of digital radiography that gives the operator contrast shift ability and may also be due to the higher experience of radiologists at the center.

In a study by Karimaneh and Najafi, $84 \%$ could be diagnosed by radiographic evaluation. ${ }^{17}$ Our study showed that of 198 cases, 185 cases were diagnosed by lateral $\mathrm{X}$ ray radiologic observation, which it was appropriate method. Pourrashidi et al., revealed that half of patients with foreign body diagnosed with X-rays. Ultrasound results were positive in $96.4 \%$ of cases. The correlation coefficient of radiographic results with sonography was significant in patients with foreign body complaints and had good agreement coefficient of 0.896 . The high coefficient of correlation between the results of ultrasound and radiography indicates that these imaging systems can be used interchangeably depending on the patient's condition and the patient's history. In fact, kappa coefficient in this study was higher than our study. The reason of this difference can be close methods of sonography and chest-x ray because both was based on radiography not observation. In our study, no association was found between the time of swallowing and the complications. While in the study of Sung et al., ${ }^{19}$ this relationship was observed. Also, in our study, the most common cause of abscess was related to fish bone, but it was not statistically significant, which could be due to lower sample size. Sung et al. revealed that the risk of complications can be increased with a longer duration of impaction, large bone and its type. In our study, high WHC was associated with high compilations, but high WBC did not necessarily indicate an abscess. In clinical traumas that were severe, we had an increase in WHC independent of infectious complications. Therefore, high WBC can indicate a complication. ${ }^{20}$ Another clinical point is this that $\mathrm{CT}$ scans shows very well the complications and it is recommended for people with drooling or high WBC.

\section{Conclusions}

According to the results, foreign bodies diagnosed with lateral neck can be reliable to take a decision based on it in patients with foreign bodies. The CT scan have a valuable role for diagnosis of complications in foreign body ingestion scenarios. Leukocytosis may be a sign of esophageal injury. In the end, we suggest performing further study in this regard comparative study with large sample is needed to conclude crucial results.

\section{References}

1. Guirgis M, Nguyen R, Pokorny C. Accidental ingestion of plastic from takeaway containers-food for thought. Med J Aust 201;194: 245-6.

2. Okhakhu AL, Ogisi FO. An unusual foreign body in human oesophagus - case report. Benin J Postgr Med 2007;9:41-3.

3. Baraka A, Bikhazi G. Oesophageal foreign bodies. Br Med J 1975;1:561-3.

4. Baral BK, Joshi RR, Bhattarai BK, Sewal RB. Removal of coin from upper esophageal tract in children with Magill's forceps under propofol sedation. Nepal Med Coll J 2010;12:38-41.

5. Comparison of the Magill forceps and the Boedeker (curved) intubation forceps for removal of a foreign body in a Manikin. J clin anesth 2012;24:25-7.

6. Akenroye MI, Osukoya AT. Uncommon, undeclared oesophageal foreign bodies. Niger J Clin Pract 2012;15: 244-6. doi: 10.4103/1119-3077.97339.

7. Vyas K, Sawant P, Rathi P, Das HS, Borse N. Foreign bodies in gut. J Assoc Phys Ind 2000; 48:394-6.

8. Shivakumar AM, Naik AS, Parashonth KB, Hongal GF, Chaturvedy G. Foreign bodies in upper digestive tract. Ind $\mathrm{J}$ Otolaryngol Head N Surg 2006;58:63-8. doi: 9.1007/ BF02907744 7

9. Pak MW, Lee WC,Fung HK, van Hassect CA. A prospective study of foreign- body ingestion in 311 children. Int J Pediatr Otorhinolaryngol 2001;58:37-45. doi: https://doi.org/10.1016/ S0165-5876(00) 00464-X.

10. Vargas EJ, Mody AP, Kim TY, Denmark TK, Moynihan JA, Barcega BB, Khan A, Clark RT, Brown L. The removal of coins from the upper esophageal tract of children by emergency physicians: a pilot study. Can J Emerg Med 2004;6:434-40.

11. Higgins GL, Burton JH, Carter WP, Floor AE. Comparison of Extraction Devices for the Removal of Supraglottic Foreign Bodies. Prehosp Emerg Care 2003;7:316-21.

12. Nouruzi-Sedeh P, Schumann M, Groeben H. Laryngoscopy via Macintosh Bladeversus GlideScope. Anesthesiol 2009;110:32-7.

13. Xue FS, Yuan YJ, Liao X, Xiong J, Wang Q. Is Glidescope ${ }^{\circledR}$ videolaryngoscope more effective than Macintosh laryngoscope for emergent intubation during chest compression? Resuscitation 2011;82:956.

14. Damghani M, Halavati N, Motamedi N. Foreign body in the upper airway and oesophagus: a seven years study from Iran. J Pak Med Assoc 2011;61:859-62.

15. Cheng W, Tam PK. Foreign-body ingestion in children: experience with 1,265 cases. J Pediatr Surg 1999; 34:1472-6.

16. Sharafi A, Taziki MH, Razaei S. Prevalence of esophageal foreign bodies and its complications in Gorgan, northern Iran (200414). J Gorgan University Med Sci 2017;19:17. Karimaneh A, Najafi M. [Esophageal foreign bodies]. Pajhohesh dar Pezeshki 2004;28:49-52. [Article in Persian]

18. Pirzadeh A, Mahdavi A, Charkhtab J. [A survey on the esophagus foreign bodies among patients in Fatemy hospital, Ardabil, 19982001]. J Ardabil Univ Med Sci. 2003;3:13-7. [Article in Persian]

19. Sung SH, Jeon SW, Son HS, Kim SK, Jung MK, Cho CM, Tak WY, Kweon YO. Factors predictive of risk for complications in patients with oesophageal foreign bodies. Dig Liver Dis 2011;43:632-5.

20. Santucci CA, Purcell TB, Mejia C. Leukocytosis as a predictor of severe injury in blunt trauma. West J Emerg Med 2008;9:81. 